Int. J. Dev. Biol. 66: 253-261 (2022)

https://doi.org/10.1387/ijdb.210213cd

\title{
Pleiotrophin, nitric oxide and glutamate AMPA receptors in chick cerebellum morphogenesis
}

\author{
VASILIKI KOMMATA, EVAGGELIA ALEXOPOULOU, \\ ELENTINA K. ARGYROUSI, CATHERINE R. DERMON*
}

Laboratory of Human and Animal Physiology, Department Biology, University of Patras, Greece

\begin{abstract}
Avian cerebellum, a highly conserved, laminated and foliated structure, provides an excellent model for developmental studies. During the intermediate embryonic stages, granule cell progenitor proliferation and the inwards migration of post-mitotic granule cells have been implicated in the morphogenesis of cerebellar cortex cytoarchitecture and foliation. The present study questioned the spatio-temporal expression pattern of pleiotrophin, an extracellular matrix growth factor, during the morphogenesis of embryonic cerebellum, and the roles of ionotropic AMPA glutamate receptors and the diffusible neuromodulator nitric oxide (NO) in the proliferation pattern of EGL granule cell progenitors. To this end, the density of proliferating cells in the developing embryonic external granule layer (EGL) was determined following acute treatment with AMPA receptor antagonist CNQX or NO synthase inhibitor L-NAME, at embryonic stages HH38-41 (E12-E15 days), by means of BrdU immunohistochemistry and double immunofluorescence. Importantly, at earlier stages, pleiotrophin-like immunoreactivity showed high expression levels in the EGL that gradually decreased, persisting within the growing folia apices, later in development. Interestingly, blockage of AMPA receptors had no effect; while NOS inhibition resulted in transient age- and region-specific increases of EGL granule progenitor cell proliferation at earlier stages, but decreased the post-mitotic granule cells at folia apices, at a later stage HH41 (E15 day). Overall, NO had a transient anti-proliferative effect in EGL similar to mammalian cerebellum, acting as a modulator of the EGL function at different stages, suggesting its possible implication in complex processes guiding cerebellar cytoarchitecture and folia formation.
\end{abstract}

KEYWORDS: cerebellum foliation, nitric oxide, glutamateantagonist CNQX, pleiotrophin, granule cell progenitors

\section{Introduction}

Cerebellum is a highly conserved foliated key-brain structure for the integration of sensory perception and the coordination of voluntary movements. During cerebellum development, in both avian and mammalian embryonic cerebellum, primary granule cell precursors migrate tangentially away from the lateral recesses of the fourth ventricle, the rhombic lip, to form a transient secondary germinal zone, the external granule cell layer (EGL) (Hanaway, 1967; Hallonet et al., 1990). EGL gradually becomes thicker and develops a complex cytoarchitecture with an outer zone of proliferating cells generating the granule cells and an inner pre-migratory zone of accumulating non-dividing, post-mitotic cells (Feirabend, 1990; Hanzel et al., 2019). Immature granule cells migrate radially inwards, along Bergmann glial fibers through the Purkinje cells to form the inner granule cell layer (Rakic, 1971; Stamatakis et al., 2004; Mecha et al., 2010; Buffo and Rossi, 2013). Studies in mammalian and avian cerebellum highlight the role of Bergmann glial cells in participating in the cerebellum cytoarchitecture (Sudarov and Joyner, 2007; Kommata and Dermon, 2018).

\footnotetext{
Abbreviations used in this paper: AMPA, a-amino-3-hydroxy-5-methyl-4isoxazolepropionic acid receptor; BrdU, 5-bromo-deoxy-uridine; CNQX, 6-cyano7-nitroquinoxaline-2,3-dione; E, embryonic day; EGL, external granule layer; FB, fissure base; FA, folium apex; GluR2/3, glutamate receptor subunits 2,3; $\mathrm{HH}$ Hamburger-Hamiltonstages; L-NAME, L-NG-Nitroargininemethylester; NO, nitric oxide; NOS, nitric oxide synthase; NMDA, N-methyl-D-aspartate; PTN, pleiotrophin
}

*Address correspondence to: Catherine R. Dermon. Laboratory of Human and Animal Physiology, Department of Biology, University of Patras, Patras, 26504, Greece. E-mail: dermon@upatras.gr | web: http://www.biology.upatras.gr/personel/dermon | https://orcid.org/0000-0002-9160-5384 
While the early mechanisms of cerebellum ontogenesis are well known, the later precise spatial and temporal events necessary to transform the avian cerebellum to a complex foliated structure with parallel lobules separated by deep fissures are not clear. A thorough study (Sudarov and Joyner, 2007) showed that EGL plays a pivotal role in the formation of cerebellum fissure architecture, while granule cells provide the driving physical force in the multicellular anchoring centers at the fissure bases, which along with coordinated action of granule, Purkinje cells and Bergmann glial fibers determine the shape of the folia. Interestingly, it has been suggested that the folding of the inner granule cell layer precedes the thickening and subsequent folding of the overlying EGL (Pena Melian et al., 1986). In turn, external granule cell proliferation pattern also contributes to the avian and mammalian cerebellar cytoarchitecture and fissure formation (Mecha et al., 2010; Kommata and Dermon, 2018). There is evidence to suggest that signal molecules e.g. neurotransmitters, sonic hedgehog, (Mecha etal., 2010), growth factors and components of the extracellular matrix (Zagris, 2001) participate in the developmental events of cerebellar histogenesis. For example, granule cell precursors express pleiotrophin (PTN), a pro-migratory secreted cytokine that reduces the rate of granule cells migration (Basille-Dugay et al., 2013) indicating a contribution by PTN to rodent cerebellar cortex development (Hamza et al., 2016). In addition, immature granule cells express excitatory glutamate receptors (Voukelatou et al., 1986; Mitsacos et al., 1990) and nitric oxide synthase (NOS) (Dermon and Stamatakis, 1994), possibly representing sites of interaction of NO and glutamate transmission signaling. While glutamate receptors have the potential to regulate neuronal NOS expression in the developing cerebellar granule cells, their role in avian cerebellum morphogenesis has yet to be determined.

Nitric oxide (NO), a gas signal molecule produced by the neuronal isoform of nitric oxide synthase (NOS), catalyzing the reaction of arginine to citrulline, is known to influence various physiological procedures and developmental events in the nervous system. Due to its diffusible nature, $\mathrm{NO}$ is characterized by a spatial postsynaptic action. Most notably, stimulation of ionotropic NMDA and AMPA glutamate receptors, trigger endogenous NO formation and cGMP signaling in hippocampal and cortical neurons (Giesen et al., 2020) as well as in the developing cerebellum (Southam et al., 1991). In turn, the NO release modulates glutamate transmission within glutamatergic neurons, downregulating AMPA receptors (Bingor et al., 2020) thus playing an important role in the major excitatory transmission in developing and adult brain.

Evidence supports the regulatory role of NO in the stem cell fate. Studies have shown that NO affects cell proliferation and adult neurogenesis, possibly contributing to the transition from cell proliferation to differentiation. Indeed, in the developing rodent brain, a transient elevation of NOS expression correlates with the cessation of the division of committed precursor cells and with the beginning of their differentiation (Bredt and Snyder, 1994). Although these observations are consistent with the notion that NO has an anti-proliferative activity, the precise role of NO in avian EGL cell proliferation and cerebellar cortex foliation needs to be clarified.

To better understand the role of EGL in the foliation events of chick cerebellum, the present study explored whether NO and a glutamate receptor antagonist have a differential effect in the progenitor granule cell proliferation at the folia apex or fissure base of the developing folium. To this end, the NOS inhibitor, L-NAME or the selective non-NMDA glutamate AMPA receptor antagonist, CNQX, were applied in ovo, during the intermediate embryonic stages when fissure formation takes place and maximum EGL proliferation is followed by massive inwards granule cell migration (stages $\mathrm{HH} 40-$ HH41, E14-E15 days). For this purpose, we studied the differential expression pattern of pleiotrophin (PTN also known HARP) during the embryonic stages under study.

\section{Results}

Embryonic cerebellum at E10 day $(\mathrm{HH} 36)$ has a smooth surface that later in development is transformed into a surface of marked folding with deep fissures giving rise to transverse folia or lobules. Cerebellar foliation and sulcus formation are evident at E11 day of incubation in accordance with the observations made by Feirabend (Feirabend, 1990). By E12 day (HH38), a primitive molecular layer, an external granular layer and inner granular layer emerge. At day E15 (HH41) all layers are distinct, the Purkinje cells appear to be organized in 1-2 rows and at mid-sagittal plane all primary lobules are present while secondary foliation is developed in folia $\mathrm{V}, \mathrm{VI}, \mathrm{VIII}$ and IX. A schematic drawing of folium VIII with secondary apices and fissure bases is shown in Fig. 1.

\section{Transient expression pattern of Pleiotrophin during embryonic development of chick cerebellum}

Interestingly, high PTN-like expression was detected at the earlier embryonic stage studied, showing intense and diffuse staining with increased expression at the external granule layer (EGL) of the developing lobules (Fig. $2 \mathrm{~A}, \mathrm{~B}$ ) at E10-E12 days (HH36+ to $\mathrm{HH} 38$ ). At E13-E15 days (HH39-HH41), PTN-like immunoreactivity gradually declined with age, but specifically persisted at the EGL lobule apices (FA) contrasting with the impressive reduction at

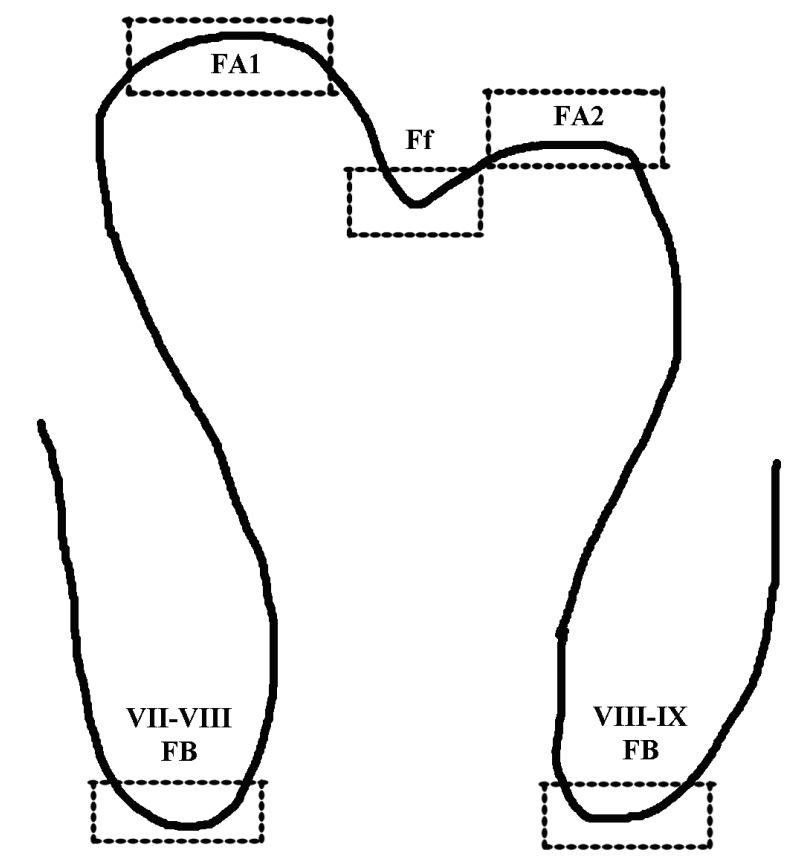

Fig. 1. Schematic representation of folium VIII. The areas of interest used to quantify the proliferating cells (BrdU+ cells) within EGL are outlined in squares, depicting sub-folium apices (FA1, FA2) and fissure bases (FB). 

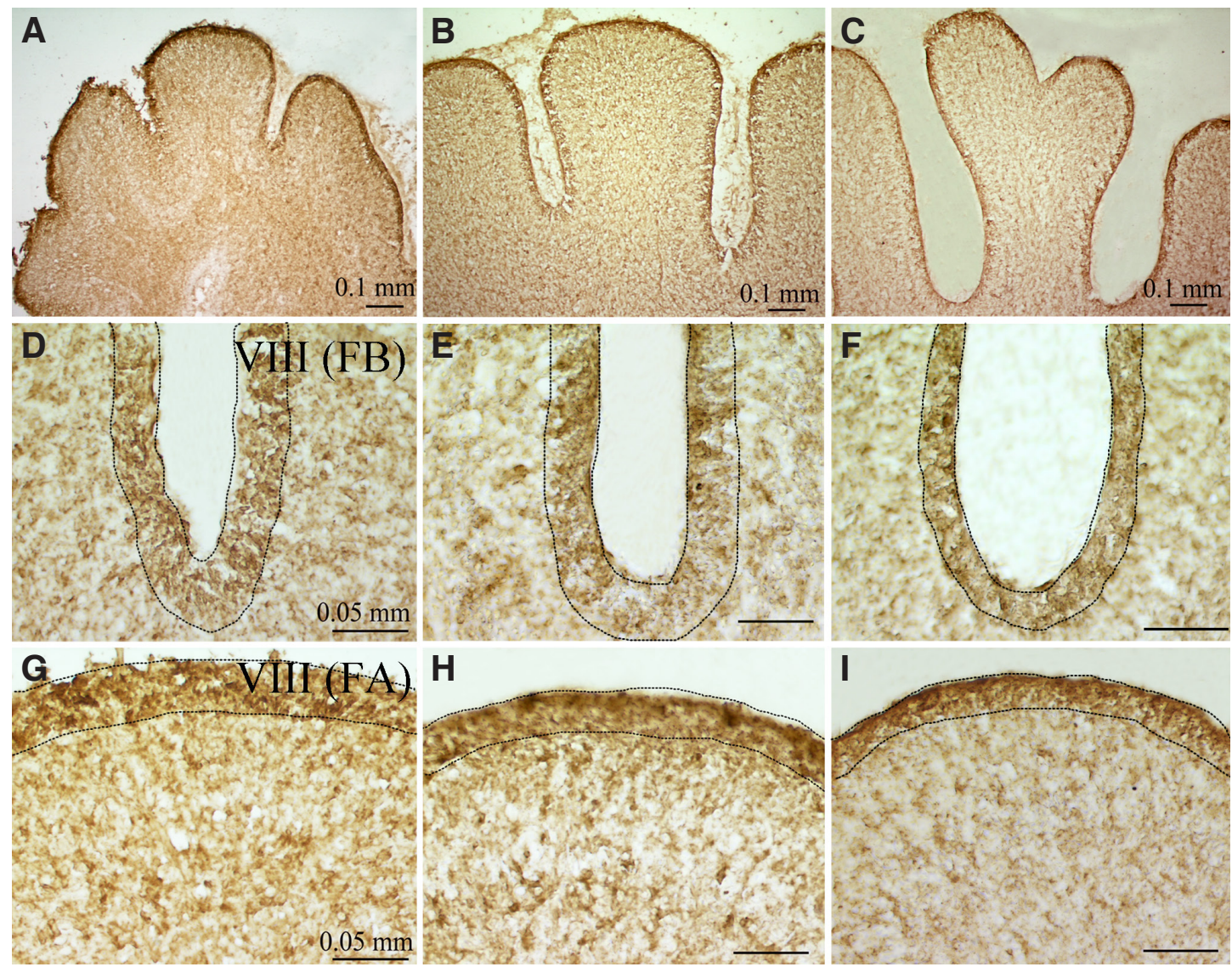

Fig. 2. PTN expression at midsagittal level of chicken cerebellum atE11-E14 embryonic days. PTN immunoreactivity was found at the cerebellum body and the external granule layer at (A) E11, (B) E12 and (C) E14 days. PTN immunoreactivity in the external granule layer at $(\mathbf{D}, \mathbf{G})$ E13 day, $(\mathbf{E}, \mathbf{H})$ E14 day and $(\mathbf{F}, \mathbf{I})$ E15 day, exhibited higher densities at $(\mathbf{G}, \mathbf{H}, \mathbf{I})$ the lobe apices compared with (D, $\mathbf{E}, \mathbf{F})$ the fissure bases.

the bases of the fissures (FB) (Fig. 2 D-I). In addition, PTN-like immunoreactivity was present in the inner granule cell layer, showing diffuse labeling. Purkinje cell bodies and their proximal dendrites were clearly not labeled, but PTN-like immunoreactivity was associated with neural and glial elements within the immature Purkinje cell and granule cell layers. At the earlier embryonic stage studied (HH36+), PTN expression was found in both the EGL zone and the main cerebellum body adjacent to the GluR2/3 immunoreactivity in the immature Purkinje cell layer (Fig. 3 A-C).

The possible anatomical relation between pleiotrophin and the mitotically active granule progenitor cells in the EGL was studied using BrdU+/PTN double immunofluorescence. At the E10 day, EGL and the inner granule cell layer showed intense PTN expression (Fig. 3 D, D'). PTN-like immunoreactivity was in close association and/or partly co-localized with a population of BrdU+ cells in the EGL. At E14 day, EGL folium apex included higher density of PTNlike labelling (Fig. 3 F,F') compared with that of the fissure base (3 $\left.E, E^{\prime}\right)$. Interestingly, a significant association of PTN labelling with BrdU+ cells was determined.

\section{CNQX treatment did not influence EGL cell proliferation in fissure base or folia apex}

The possible differential effect of CNQX, a non-NMDA antagonist (Fig. 4), on the granule cell proliferation rate of EGL zone of cerebellum was studied at E14-E15 days, when a massive inwards granule cell migration takes place to shape the final cerebellar architecture. Preliminary experiments of CNQX application at earlier stages
$\mathrm{HH} 38-\mathrm{HH} 39$ (E12-E13 days) had a great impact on the survival of the embryos. At stage HH40 (E14 day), acute (4h, 5mM) CNQX application showed a trend in decreasing the proliferation rate of BrdU+ cells (Fig. 4 A,B), with no statistically significant effect on either fissure base $\left(F_{1,9}=0.814 P=0.390\right)$ or folia apex $\left(F_{1,9}=0.051\right.$ $\mathrm{P}=0.826$, Fig. 4C).

NOS inhibition showed a differential effect on EGL cell proliferation depending on the developmental stage and folium sub-region

Granule cell genesis was evaluated following 4 hours of acute treatment of the NOS inhibitor L-NAME (Fig. 5). At fissure base, statistical analysis showed no significant interaction $\left(F_{3,14}=2.135\right.$, $p=0.142)$ but only a simple main effect $\left(F_{1,14}=5,951 P=0.029\right)$. In contrast, an interaction effect of treatment and developmental stage was found in folia apex $\left(F_{3,14}=4,299 P=0.021\right)$, specifically at $E 12$ $\left(\mathrm{t}_{4}=-4,51, \mathrm{P}=0.006\right)$ and $\mathrm{E} 15$ days $\left(\mathrm{t}_{4}=3.44 \mathrm{P}=0.026\right)$ (Fig. $\left.5 \mathrm{C}\right)$. At E12 day (HH38) (Fig. 5A) a significant increase in BrdU+ cell density of EGL zone was observed specifically in both sub-folium apices, FA1 $\left(t_{4}=-3.143 P=0,035\right)$ and FA2 $\left(t_{4}=-5,295 P=0.006\right)$. In contrast, at $E 15$ day $(\mathrm{HH} 41)$ (Fig. 5B), the number of BrdU+ cells showed a decrease in both sub-folium apices, following L-NAMEtreatment, FA1 $\left(t_{4}=5,422\right.$ $p=0,006)$ and FA2 $\left(t_{4}=3,464 P=0.026\right)$. Interestingly, NOS inhibition did not show an interaction of treatment and developmental stage in the density of BrdU+ proliferating cells in the fissure base (Fig. $5 \mathrm{C}$ ). These findings suggest that during the time window examined, inhibition of NOS activity had developmental stage- and folium subregion- specific effects on granule cell proliferation. 

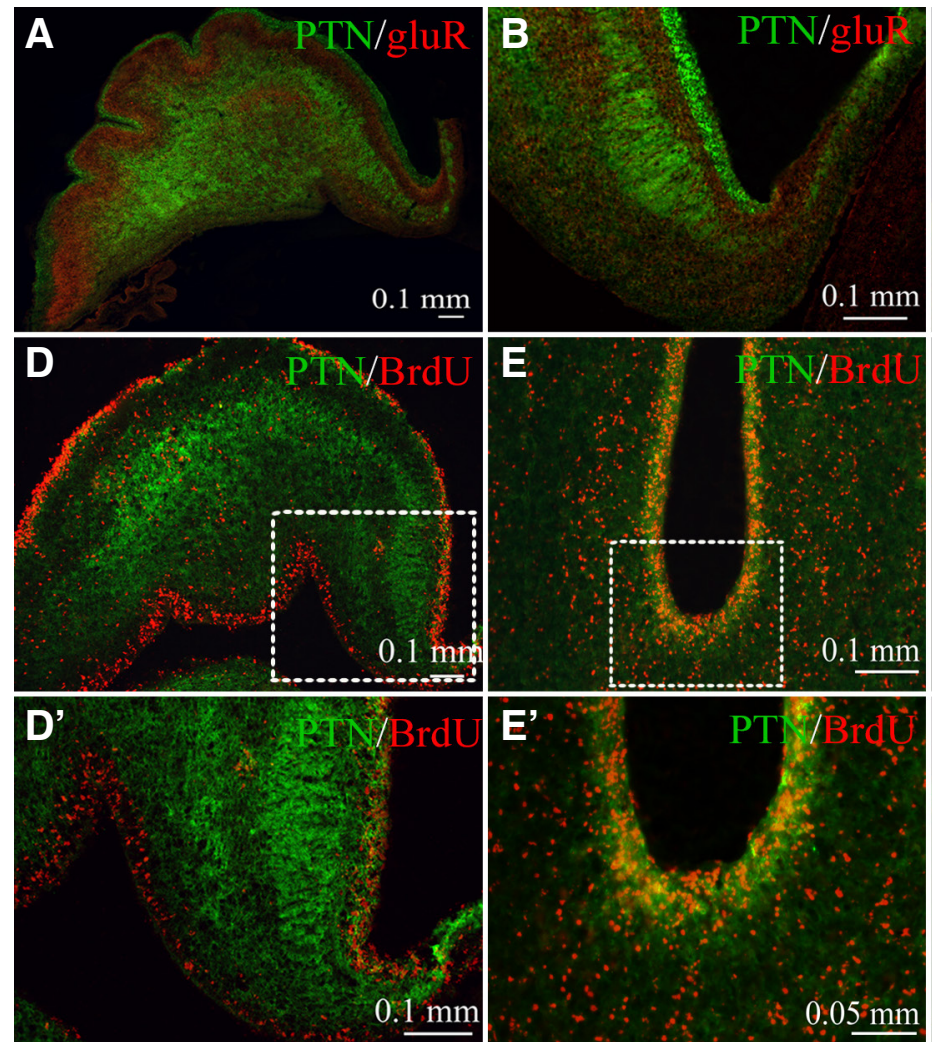

\section{Discussion}

The proliferation of granule cell precursors, along with the Purkinje cell layer folding and the orientation of Bergman glial fibers, are known to contribute to mammalian cerebellum cytoarchitecture and foliation (Sudarov and Joyner, 2007). It is a well-known fact that chicken EGL begins to form at E6 day of incubation (HH32), and by E10 day (HH36) it covers most of the cerebellar cortex, reaching its maximum at stage HH41 (E15 day) (Hanaway, 1967). Considering the differences in the EGL cell proliferation rate between the folium base and apex (Kommata and Dermon, 2018), we hypothesized a possible role of glutamate AMPA receptors or NO signaling in shaping these differences contributing to the folium formation. Indeed, inhibition of NO synthase activity resulted in a statistically significant interaction effect on the mitotic activity within the EGL covering the apex of primary and secondary sulcus of folium VIII, while blockage of AMPA receptors by CNQX had no effect. Interestingly, pleiotrophin showed a transient spatio-temporal expression pattern, persisting at EGL folia apex, suggesting its possible involvement in folium growth.

\section{EGL covering the fissure apex showed a higher expression of pleiotrophin-like immunoreactivity}

Pleiotrophin (PTN), a 136-amino acid sequence, binds the proteoglycans syndecan 3 (SDC-3) and protein tyrosine phosphatase $\zeta$ (PTP $\zeta$ ) and is conserved throughout various species (Rauvala, 1989). In mammals, pleiotrophin is known to be strongly expressed at birth in a strictly spatio-temporal pattern (Rauvala, 1989). Pleiotrophin-like immunoreactivity in chick embryonic cerebellum was generally in line with that previously described in mammals, showing high density of diffuse labeling within the EGL and the main
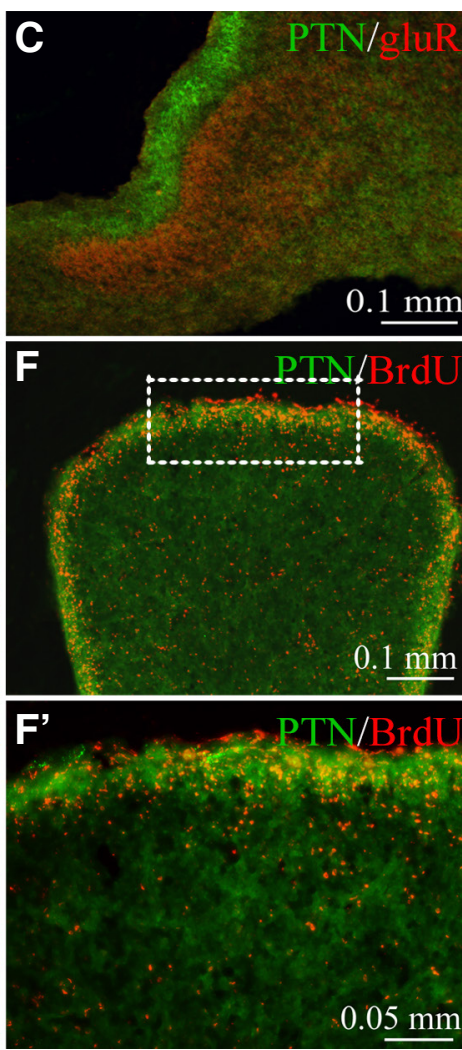

Fig. 3. Double immunofluorescence of the PTN expression in association with GluR2/3 glutamate AMPA receptors and proliferating granule progenitor cells in EGL. (A-C) Expression pattern of PTN in the EGL and cerebellum body is complementary to GluR2/3 in the immature Purkinje cell layer at E10 day. (D-F') Co-localization of pleiotrophin with the BrdU+ cells in the externa granule layer of the developing chick cerebellum. (D, D') At E10 day, PTN was found in close association with EGL BrdU+ cells. (E, F') At E14 day pleiotrophin was co-localized with a population of proliferating BrdU+ cells at the external granule layer of (E, $\left.\mathbf{E}^{\prime}\right)$ fissure base and (F, $\left.\mathbf{F}^{\prime}\right)$ folium apex. Insert squares in $\mathbf{D}, \mathbf{E}$, $\mathbf{F}$ are shown in higher magnification in $D^{\prime}, E^{\prime}, F^{\prime}$.

body of chick cerebellum at the earlier stages studied. Pleiotrophin (PTN) has been shown to regulate rodent cerebellar histogenesis, participating in the radial migration of granule cells progenitors through the molecular layer (Basille-Dugay et al., 2013). There is also evidence suggesting that PTN participates in Purkinje cells morphogenesis, inducing an atrophy of the Purkinje cell dendritic tree mediated via chondroitin sulfate proteoglycan, PTP $\zeta$ signaling (Tanaka et al., 2003), both by direct activation on PTP $\zeta$ receptors exposed on the neuronal membrane and by activation on the same receptors on Bergman glial cell (Buffo and Rossi, 2013). In support, perinatal PTN administration in mice induced a significant decrease of the surface of the dendritic tree associated with an increase in excitatory postsynaptic transmission and an abnormal somatic localization of granule cells parallel fiber connections (Hamza et al., 2016)

Although there are suggestions that PTN is expressed in the radial fibers in rats, evidence from the developing mouse cerebellum demonstrated that PTN is probably not produced by the Bergmann glial cells but by a different cell population that could release it into the extracellular matrix (Basille-Dugay et al., 2013). Interestingly, the same study showed that EGL and cultured granule cells exhibited strong PTN expression, indicating that the granule cell progenitors could be the major source of cerebellar PTN. However the PTN receptor PTP $\zeta$ was found to be expressed in radial glial fibers, around the Bergmann and the Purkinje cell bodies but not in the EGL (Basille-Dugay et al., 2013). Likewise, in the present study, we found a similarly high pleiotrophin expression within the $E G L$, further suggesting that granule cell progenitors may express PTN, influencing chick cerebellum morphogenesis. However, future studies are necessary to detemine whether the PTN signaling in embryonic chick cerebellar cortex is also mediated via receptors 
located in the Purkinje and/or the Bergmann cells, as suggested for the mouse cerebellum. In addition, the transient PTN expression profile in EGL was characterized by a close association, as well as a partial co-localization with BrdU+ cells, favoring the hypothesis of PTN's potential to influence granule cell proliferation, maturation and initiation of migration. Indeed, high PTN expression persisted specifically in the external granular layer covering the growing folia apices, which are characterized by a higher rate of proliferating cells compared with the fissure bases. Therefore, higher PTN expression coincided with higher mitotic activity of granule progenitor cells, suggesting that PTN is important for maintaining the newborn granule cell production rate in the folia apex supporting normal folium growth. This notion is supported by the fact that adult hippocampal neural stem cells continuously release pleiotrophin as a signal to maintain the functional neural stem niche and regulate the maturation of newly generated newborn neurons (Tang et al., 2019).

\section{Blockage of glutamate AMPA receptors had no effect on EGL cell proliferation rate}

Purkinje cells, the largest neuronal cell type in the cerebellar cortex with the most elaborate synaptic interactions in the cerebellum, play a critical role in the proliferative activity of granule cell progenitors (Sudarov and Joyner, 2007; Mecha et al., 2010). Glutamate AMPA receptors, the primary mediators of fast excitatory synaptic transmission in the vertebrate brain, often co-localized with NMDA receptors, are the dominant glutamate receptors in Purkinje cells including GluR2/3 receptor subunits (Monyer et al., 1991). Functionally, ionotropic AMPA glutamatergic receptors have been implicated in synaptic plasticity, remodeling, LTD modulating the influx of $\mathrm{Na}+$ into the Purkinje cell dendrites (Kuruma et al., 2003). Quantitative autoradiographic studies have shown that $\left[{ }^{3} \mathrm{H}\right]$ CNQX binding sites of nonNMDA glutamate receptors are densely localized in the molecular layer of chick cerebellum (Mitsacos et al., 1990; Zavitsanou et al., 1994). Importantly, the AMPA-type glutamate receptors are the first ionotropic GluRs to appear during chick brain development (Voukelatou et al., 1986) and can regulate differentiation and plasticity

Fig. 4. Acute (4h) CNQX effects on EGL granule cell proliferation Microphotographs showing BrdU labelling of EGL in control and CNQX-treated embryos at (A) E14 day and (B) E15 day of fissure base (FB) and folia apex (FA) of the developing lobule VIII. (C) Bar graphs showing the densities of BrdU+ cells in the EGL at E14 and E15 days. No statistically significant difference was determined following CNQX administration. Scale bar $0.05 \mathrm{~mm}$. events even before synaptogenesis. Interestingly, while AMPA receptors are present in chick cerebellum during the embryonic stages studied, acute treatment with the AMPA receptor antagonist CNQX had no effect on the EGL granule cell proliferation pattern of the sub-regions of growing VIII lobule.

Previous studies have shown how glutamate AMPA receptors affect the telencephalic ventricular and subventicular zone. Specifically, administration of $10 \mu \mathrm{M} C N Q X$ tended to prolong the duration of cell cycle in the ventricular zone (Haydar et al., 2000), while NMDA and AMPA glutamate receptor antagonists increased granule cell neurogenesis from pre-existing neural precursors in hippocampal slice cultures (Poulsen et al., 2005). Although there is evidence of the effect of AMPA receptors upon cortical and hippocampal neural progenitors, the present study showed that this is not the case for cerebellar granule cell progenitors, at least during the embryonic stages $\mathrm{HH} 40-\mathrm{HH} 41$ (E14-E15 days) studied, when lobule elongation is accompanied by maximum EGL cell proliferation and migration. It must be noted here that unlike the ventricular zone neural precursors, EGL granule progenitor cells divide symmetrically to expand the progenitor pool and subsequently produce differentiated neurons, and therefore may involve different signaling. Whether or not glutamate AMPA receptors participate in foliation events of chick cerebellum via different mechanisms, e.g. granule cell migration or other activity-depended interactions of granule and Purkinje cells, needs to be further investigated.

\section{Inhibition of NOS showed transient complex effects on EGL cell proliferation at the folia apices}

Nitric oxide (NO) synthesized by neuronal nitric oxide synthase is implicated in developmental processes of neuronal survival, differentiation, precursor proliferation and neurotransmission. Nitric oxide is known to act as a negative regulator of neurogenesis in

\section{A}

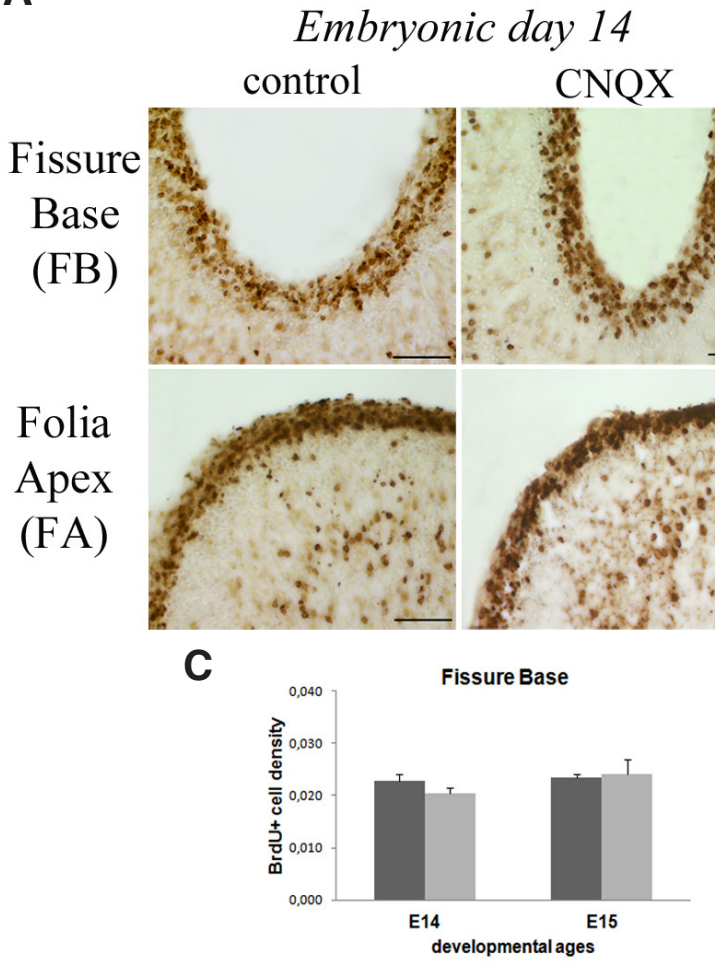

B

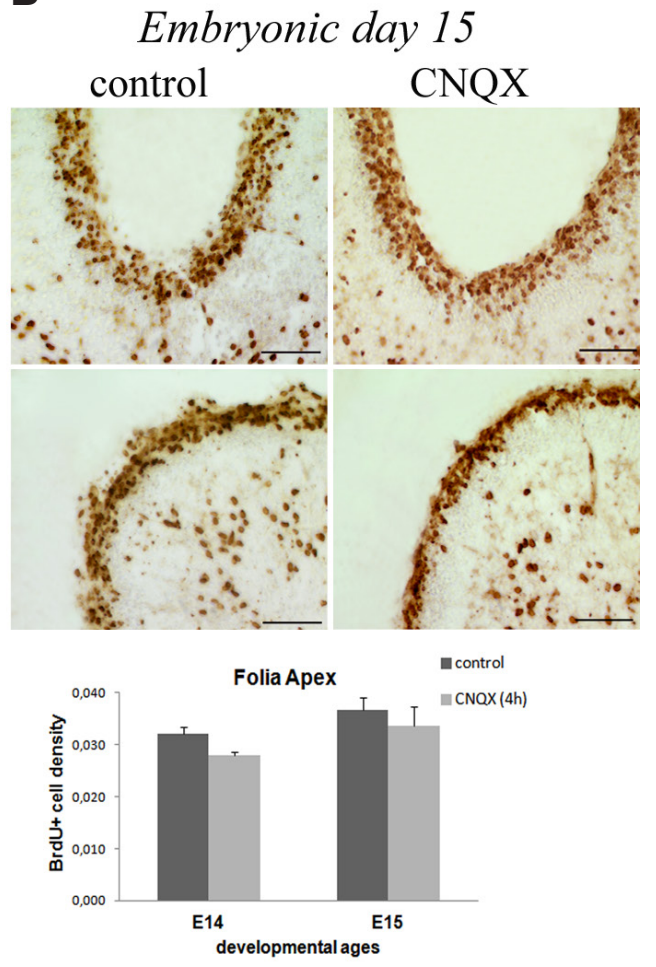


mammalian granule cell precursor proliferation, promoting its survival and differentiation (Contestabile, 2012). Meanwhile, studies in knocked down mice for the neuronal nitric oxide synthase isoforms resulted in neuronal precursor proliferation decreases in the olfactory epithelium (Chen et al., 2004). In embryonic chick cerebellum, NOS expression has been shown to increase with age, with NOS expressing fibers found to run radially through the cerebellar cortex from the inner granule layer to the external granule layer (Dermon and Stamatakis, 1994). Interestingly, in the present study, pharmacological NOS inhibition exhibited both positive and negative effects, influencing transiently cerebellum EGL granule cell proliferation at the folium apex, depending on the developmental stage. Specifically, at E12 day, when EGL is increasing in thickness, acute NOS inhibition resulted in a significant increase in BrdU+ cell density at the folium apex, in accordance with the negative role of NO in neurogenesis. In support, previous studies have shown that the pharmacological inhibition of NOS increased proliferation of neural precursors isolated from the postnatal mouse subventricular zone (Matarredona et al., 2004), and in the chick neural tube (Plachta et al., 2003). However, at a later developmental stage - HH41 (E15 day) - NOS inhibition decreased the density of folia apex EGL BrdU+ cells, possibly suggesting that at this stage NO has a positive role in newborn post-mitotic granule cell survival. Indeed, at that stage, a massive inwards migration

A
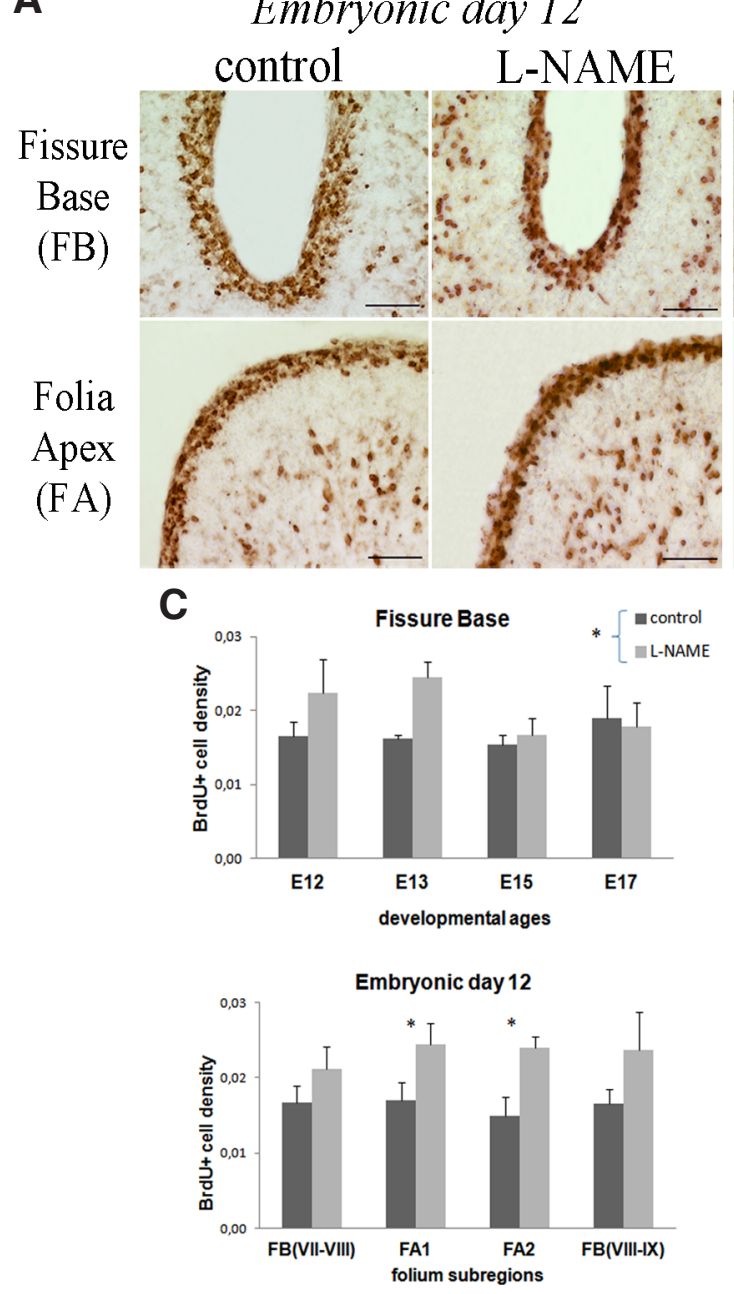

B Embryonic day 15
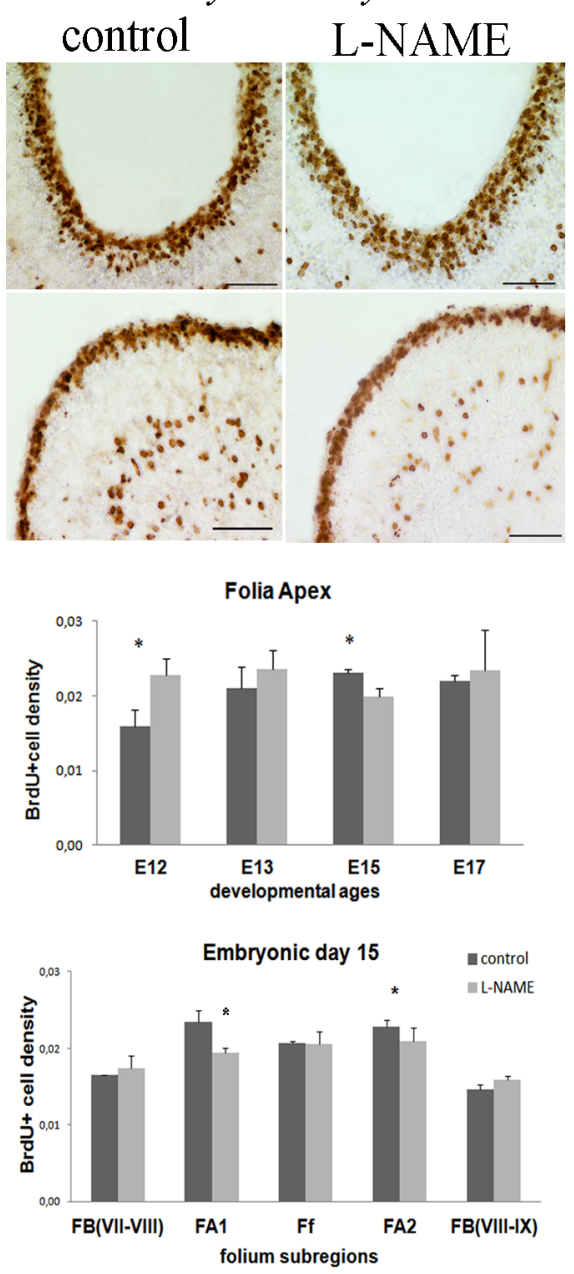

of immature granule cells begins, suggesting a possibly different physiological role of NO from previous stages, when the pool of progenitor cells is rapidly increasing. Moreover, in vitro studies in granule cell cultures indicate that NO reduction increased apoptotic death and that NO is necessary to sustain the survival of differentiating granule neurons (Ciani et al., 2002). It is therefore suggested that NO reduction, by NOS inhibition at E15 day, may have an impact on the survival of BrdU+ newborn granule cells at the pre-migratory EGL zone. In accordance with our findings, a study in rat pups reported that pharmacological blockade of nitric oxide during a restricted time window of the first three postnatal days resulted in an increased proliferation rate, but not at later (postnatal days 3 to 7) developmental stages (Ciani et al., 2006).

At present, the underlying mechanisms of the transient NO effects upon chick granule cell proliferation are not known. A hypothesis may involve different NO signaling in relation to a homeostatic role of $\mathrm{NO}$ at the different developmental stages. In other words, NO may serve as a negative regulator at early stages when the precursor cell pool needs to be controlled to avoid excessive growth, while at later stages, when cell progenitors are reduced and post-mitotic cells are produced, NO signaling may act positively on newborn cell survival. The NO signaling downregulating mammalian granule cell precursors is antagonistic to Shh cellular cascades (Contestabile, 2012) and is thought to involve cGMP. In rat cerebellar slices, most NO-induced CGMP was found in glial cells, and is thus involved in indirect regulation of proliferating granule cell precursors by Bergman glia in the developing cerebellum (De Vente et al., 1990). Indeed, in chick cerebellum, NOS expressing radial fibers extend up to the EGL pre-migratory zone before the time newborn granule cell differentiate and start their inward migration (E9-E15 day), suggesting that the NO produced by these fibers may signal the end of proliferation and the initiation of massive granule cell migration (Dermon and Stamatakis, 1994). Interestingly, as in mammals, NOS expression increased with the differentiation of granule cells, and at the time synaptic contacts from climbing fibers are made, it is transiently located

Fig. 5. Acute (4h) L-NAME effects on EGL granule cell proliferation. Microphotographs showing BrdU labelling of EGL in control and L-NAME-treated embryos at (A) E12 day and (B) E15 day of fissure base (FB) and folia apex (FA) of the developing lobule VIII. (C) Bar graphs showing the densities of BrdU+ cells in the EGL at E12 -E17 days and the developing sub-lobules of lobule VIII fissure base and folia apex at E12 and E15 days. Statistically significant effects were determined in sub-folia apex at E12 and E15 days. ${ }^{*} p=0.05$. Scale bar $0.05 \mathrm{~mm}$. 
on the Purkinje cell somata. From E15 day, NOS is expressed by the migrating granule cells and their formation of parallel fibers left behind in the molecular layer (Dermon and Stamatakis, 1994). In agreement, NO signaling appears to stimulate granule cell migration and maturation of parallel fibers in mammalian cerebellum (Tellios et al., 2020). Furthermore, inhibition of endogenous NOS activity by L-NAME appeared to delay Purkinje cell dendritic branching (Tellios et al., 2020), implying that NO producing granule cell excitatory parallel fibers may contribute to Purkinje cell normal maturation and cerebellar cytoarchitecture. Overall, the present study provides evidence of the role of nitric oxide as a modulator of neurogenesis in avian cerebellum similar to mammals, with transient effects on granule cell genesis, negatively influencing EGL cell proliferation depending on the developmental stage. Further studies are necessary to clarify the possible underlying mechanisms of the NO role in chick cerebellar cortex morphogenesis, acting as a modulator of EGL physiological functions during the different developmental stages.

\section{Materials and Methods}

\section{Experimental animals, treatments and tissue preparation}

Fertilized chicken eggs (Gallus domesticus), were incubated in a humidified brooder at $37.8^{\circ} \mathrm{C}$. The first day of the incubation was assigned as embryonic day 0 (E0). At E12 to E17 days (HH38-HH43; Hamburger and Hamilton, 1992), L-N $\mathrm{N}^{\mathrm{G}-N i t r o a r g i n i n e}$ methyl ester (L-NAME saline solution, (3mg/200ul, $56 \mathrm{mM})$, or 6-cyano-7-nitroquinoxaline-2.3-dione selective AMPA antagonist (CNQX saline solution, 0,3mg/200ul, $5 \mathrm{mM}$ ) were applied in ovo, under sterile conditions. Injections of $200 \mu$ l were performed on the air sac known to permit rapid entrance into the blood stream. Matched control embryos were treated with saline. In addition, control embryos from E10 to E17 days were used to determine pleiotrophin expression pattern.

To label mitotically active cells, the 5-bromo-deoxy-uridine (BrdU) method was applied, based on the BrdU, a thymidine analogue, incorporated into the DNA during the S-phase of the cell cycle (Stamatakis et al., 2004). At all stages studied, one hour following acute treatment with L-NAME or CNQX, embryos were injected in the air sac, with $\mathrm{BrdU})(80 \mu \mathrm{g} / \mathrm{gr}$ egg weight in physiological saline, $5 \mathrm{mM}$ ), and were allowed to survive for 3 hours. It should be noted that a single injection of BrdU labels the nuclei of cells that are in the S-phase, but not the nuclei of proliferating cells that are in other phases of the cell cycle.

Following treatment, embryos were anaesthetized and transcardially perfused with $0.9 \%$ saline and then by a fixative solution (4\% paraformaldehyde, PFA, in $0.1 \mathrm{M}$ phosphate buffer, $\mathrm{pH}=7.4$ ). The brains were removed, cryoprotected at $4^{\circ} \mathrm{C}$ overnight in $20 \%$ sucrose in $4 \%$ PFA, frozen in isopentane at $-40^{\circ} \mathrm{C}$ and kept at $-80{ }^{\circ} \mathrm{C}$ until processing. Mid-sagittal sections, $20 \mu \mathrm{m}$ thick, were prepared using a cryostat/cryotome (Leica CM 1500). Cutting protocol was adjusted per developmental stage allowing serial sections distance of $120 \mu \mathrm{m}$ at E12 day and $160 \mu \mathrm{m}$ at E15-17 days. Sections were thaw-mounted on gelatin-coated slides and processed for single and double immunohistochemistry.

All experimental procedures were in accordance with Greek (PD 56/2013) and EU (Directive 63/2010) legislation on the care and use of experimental animals. Efforts were made to minimize animal suffering and to reduce the number of animals used.

\section{Immunohistochemisty}

For BrdU immunohistochemistry, sections were incubated for $2 \mathrm{~h}$ in $50 \%$ formamide/2xSSC in $65^{\circ} \mathrm{C}$, to denature DNA, followed by $2 \mathrm{~N} \mathrm{HCl}$ for $30 \mathrm{~min}$ at $37^{\circ} \mathrm{C}$. The sections were then rinsed in PBS ( $4 \times 5$ min and $1 \times 10 \mathrm{~min}$ ), immersed in blocking solution (5\% BSA, $1 \%$ horse normal serum, $0.1 \%$ Triton $X-100$ in PBS) for 30 min, at room temperature and incubated overnight at $4^{\circ} \mathrm{C}$ with a mouse anti-BrdU monoclonal antibody (Becton-Dickinson), diluted $1: 100$ in $0.1 \%$ Triton $X-100$ in PBS. Sections were then rinsed in PBS ( $3 \times 5 \mathrm{~min})$, incubated in biotinylated anti-mouse IgG antibody (Vector Labs, 1:200 in PBS) for $2 \mathrm{~h}$ at room temperature. They were then rinsed in a $0.1 \%$ Triton $\mathrm{X}-100$ in PBS, $\mathrm{pH}=7.4$, incubated in an avidin-biotin-peroxidase solution (Vector labs, $A B C$ elite kit; solutions $A$ and $B$ diluted 1:100 in 0.1\% Triton $X-100$ in PBS) for 1 $\mathrm{h}$ in the dark at room temperature (Dermon et al., 2002; Kommata and Dermon, 2018), followed by consecutive rinsing in PBS. BrdUpositive cells were visualized using diaminobenzidine (DAB, Vector Labs SK-4100) as chromogen. The reaction was terminated by repeated washes in cold $\mathrm{PBS}, \mathrm{pH}=7.4$. Sections were dehydrated and coverslipped with Entellan (Merck).

Single immunohistochemistry was applied in adjacent sections for the determination of the expression pattern of a growth factor with high affinity for heparin, pleiotrophin (PTN). Specifically, a goat Anti-Human Pleiotrophin/PTN Antigen Affinity-purified Polyclonal Antibody (R\&D systems Catalog \# AF-252-PB) was used. Briefly, sections were allowed to dry, followed by a 7 min wash in $\mathrm{H}_{2} \mathrm{O}_{2}$ (1.5\%) and immersion in blocking solution (5\% BSA, 1\% normal horse serum, $0.1 \%$ Triton X-100 in PBS) for 30 min at room temperature. Sections were then incubated for two overnights at $4^{\circ} \mathrm{C}$ with goat anti-PTN (1:200). On the third day, sections were rinsed in PBS ( $3 \times 5 \mathrm{~min})$, incubated in biotinylated anti-goat IgG antibody (Vector Labs, 1:200 in PBS) for $2 \mathrm{~h}$ at room temperature, rinsed in a $0.1 \%$ Triton $\mathrm{X}-100$ in PBS, $\mathrm{pH}=7.4$, and incubated in an avidinbiotin-peroxidase solution (Vector labs, ABC elite kit; solutions $A$ and $B$ diluted $1: 100$ in $0.1 \%$ Triton $X-100$ in PBS) for $1 \mathrm{~h}$ in the dark at room temperature, visualized using DAB as chromogen. Sections were dehydrated and cover-slipped with Entellan (Merck).

\section{Double immunofluorescence}

To determine the anatomical relation s of Pleiotrophin-like expression with the active proliferating EGL BrdU+ cells and GluR2/3 AMPA receptor subunits, double immunofluorescence was performed. Adjacent sections were washed $(2 \times 5 \mathrm{~min})$ in phosphate buffer (0.01M PBS pH 7.4), immersed in blocking solution (5\%BSA, $0.15 \%$ NHS, PBST) for 30 min at room temperature and incubated for two overnights at $4^{\circ} \mathrm{C}$ with a cocktail of a combination of the primary antibodies of mouse anti-BrdU with goat anti-Pleiotrophin (BrdU/ PTN) and goat anti-Pleiotrophin with rabbit anti-GluR2/3 (Chemicon, Catalog \# 07-598, PTN/GluR2/3) in PBST. On the second day, sections were incubated with a cocktail of appropriate secondary antibodies (Alexa fluor Molecular Probes, 1:400) for 2 hours at room temperature, donkey anti-goat 488 and donkey anti-mouse 555 (for BrdU/PTN), donkey anti-goat 488 and donkey anti-rabbit 555 (for PTN/GluR2/3). Sections were dried in the dark and coverslipped using a mounting medium (Vector Labs, $\mathrm{H}-1400$ ).

\section{Specificity of antibodies}

To test the antibodies' specificity, negative control experiments were carried out in adjacent sections, with the omission of the 
primary antibodies or the secondary antibody and the application of secondary antibodies, mismatched for species. All control experiments resulted in no immunohistochemical staining of PTN, GluR2/3 or BrdU.

A purified mouse anti-BrdU, Clone B44 (Becton Dickinson) was used to detect active proliferating cells showing similar staining with previous studies (Dermon et al., 2002; Stamatakis et al., 2004) A rabbit polyclonal anti-Glutamate AMPA R2/3, against synthetic peptide corresponding to amino acids $864-883$ of the C-terminus of rat GluR2 which recognizes human, rat, mouse, monkey and chicken GluR2/3, was used. By immunoblotting of rat brain tissue homogenates, the antibody stains a single band co-migrating with GluR2 and GluR3 at approximately 110kDa (Chemicon datasheet) and at 98kDa in chick cerebellum (Pires et al., 2010). The expression pattern in Purkinje cell somata and apical dendrites observed in the present study is similar to that in the mammalian cerebellum. The PTN antibody used is an antigen affinity-purified polyclonal goat IgG that detects human pleiotrophin in direct ELISAs and Western blots (R\&D, specification sheet). The present expression pattern in chick cerebellar cortex has similar features to that previously reported for mammalian cerebellum (Basille-Dugay et al., 2013).

\section{Microscopic quantification, statistical analysis, photomicrograph production}

Sections were observed using a light microscope and fluorescence microscope(Nikon Optiphot-2). High-resolution microscopic images were captured using a color CCD Sony DXC-950P camera connected to the microscope. Figures were prepared for publication with Adobe Photoshop CS5 (Adobe System Inc., San Jose, CA).

Cerebellar lobules/folia were numbered from I to X (from rostral to caudal) and were identified based on the Larsell's nomenclature (1967). The primary folia are the main folia, whereas the secondary folia are formed after subfoliation of the primary folia during embryonic development of the cerebellum (Feirabend, 1990). The rate of proliferating cells was expressed as the density of BrdU+ cells $\left(\mathrm{BrdU}^{+}\right.$cell number/ surface $\left.\mu \mathrm{m}^{2}\right)$ within the different sub-folia regions (Fig. 1) studied at mid-sagittal levels of the growing lobule VIII (X600), known to receive pontine, trigeminal and hippocampal afferents (Arends and Zeigler, 1989; Liu et al., 2012). Specifically, the mitotically active cells were determined at the most folded part of the fissure (fissure sulcus or base, FB) and at the apex area of the developing folium (folium apex, FA) (Fig. 1), as previously described (Bowers and Atkins, 2004). The number of BrdU+ cells was determined within the EGL of FB or FA areas, using a measurement frame of $0.06 \mathrm{~mm}^{2}$. The quantification of the EGL surface and BrdU+ cells was performed in 3-4 embryos per stage, in at least 3 sections at mid-sagittal level per cerebellum. Statistical analysis of two-way analysis of variation (ANOVA) was applied, followed by independent comparison t-test (when a significant interaction was found). Using SPSS Statistics (V22), analyses of the CNQX and L-NAME effects on the BrdU+ cell density within EGL FA or FB surfaces $\left(\mu \mathrm{m}^{2}\right)$, were performed with treatment and age as independent variables. A probability level of $5 \%(P<0.05)$ was considered statistically significant.

\section{Acknowledgements}

Part of the work was supported by Andreas Mentzelopoulos Scholarship to VK. We thank Emmanouil Mavrogiannis and Nikolaos Tzanotis for technical support. We thank Prof Nikolaos Zagris for stimulating discussions that initiated the pleiotrophin study in chick embryonic cerebellum.

\section{References}

ARENDS J.J.A., PHILIP ZEIGLER H. (1989). Cerebellar connections of the trigeminal system in the pigeon (Columbia livia). Brain Research 487: 69-78. https://doi. org/10.1016/0006-8993(89)90941-4

BASILLE-DUGAY M., HAMZA M. M., TASSERY C., PARENT B., RAOULT E., BÉNARD M., RAISMAN-VOZARI R., VAUDRY D., BUREL D. C. (2013). Spatio-temporal characterization of the pleiotrophinergic system in mouse cerebellum: Evidence for its key role during ontogenesis. Experimental Neurology 247: 537-551. https:// doi.org/10.1016/j.expneurol.2013.02.004

BINGOR A., HAHAM T., THORNTON C., STERN-BACH Y., YAKA R. (2020). Zeta Inhibitory Peptide attenuates learning and memory by inducing NO-mediated downregulation of AMPA receptors. Nature Communications 11: 3688. https:// doi.org/10.1038/s41467-020-17484-y

BOWERS D. F., ATKINS D. L. (2004). Avian fissura prima: Differential accumulation of extracellular matrix at a fold. Journal of Morphology 262: 780-790. https://doi. org/10.1002/jmor.10278

BREDT D. S., SNYDER S. H. (1994). Transient nitric oxide synthase neurons in embryonic cerebral cortical plate, sensory ganglia, and olfactory epithelium. Neuron 13: 301-313. https://doi.org/10.1016/0896-6273(94)90348-4

BUFFO A., ROSSI F. (2013). Origin, lineage and function of cerebellar glia. Progress in Neurobiology 109: 42-63. https://doi.org/10.1016/j.pneurobio.2013.08.001

CHEN J., TU Y., MOON C., MATARAZZO V., PALMER A. M., RONNETT G. V. (2004) The localization of neuronal nitric oxide synthase may influence its role in neuronal precursor proliferation and synaptic maintenance. Developmental Biology 269: 165-182. https://doi.org/10.1016/j.ydbio.2004.01.024

CIANI E., CALVANESE V., CROCHEMORE C., BARTESAGHI R., CONTESTABILE A. (2006). Proliferation of cerebellar precursor cells is negatively regulated by nitric oxide in newborn rat. Journal of Cell Science 119: 3161-3170. https://doi. org/10.1242/jcs.03042

CIANI E., VIRGILI M., CONTESTABILE A. (2002). Akt pathway mediates a cGMPdependent survival role of nitric oxide in cerebellar granule neurones. Journal of Neurochemistry 81:218-228. https://doi.org/10.1046/j.1471-4159.2002.00857.x

CONTESTABILE A. (2012). Role of Nitric Oxide in Cerebellar Development and Function: Focus on Granule Neurons. The Cerebellum 11: 50-61. https://doi. org/10.1007/s12311-010-0234-1

DE VENTE J., MANSHANDEN C. G., SIKKING R. A., RAMAEKERS F. C. S., STEINBUSCH H. W. M. (1990). A functional parameter to study heterogeneity of glial cells in rat brain slices: Cyclic guanosine monophosphate production in atrial natriuretic factor (ANF)-responsive cells. Glia 3: 43-54. https://doi.org/10.1002/ glia.440030107

DERMON C. R., STAMATAKIS A. (1994). Laminar pattern of NADPH-diaphorase activity in the developing avian cerebellum. NeuroReport 5: 1941-1945. https:// doi.org/10.1097/00001756-199410000-00025

DERMON C.R., ZIKOPOULOS B., PANAGIS L., HARRISON E., LANCASHIRE C. L., MILEUSNIC R., STEWART M.G. (2002). Passive avoidance training enhances cell proliferation in 1-day-old chicks. European Journal of Neuroscience 16: 1267-1274. https://doi.org/10.1046/j.1460-9568.2002.02177.x

FEIRABEND H. K. (1990). Development of longitudinal patterns in the cerebellum of the chicken (Gallus domesticus): a cytoarchitectural study on the genesis of cerebellar modules. European journal of morphology 28: 169-223.

GIESEN J., FÜCHTBAUER E.M., FÜCHTBAUER A., FUNKE K., KOESLING D., RUSSWURM M. (2020). AMPA Induces NO-Dependent cGMP Signals in Hippocampal and Cortical Neurons via L-Type Voltage-Gated Calcium Channels. Cerebral Cortex 30: 2128-2143. https://doi.org/10.1093/cercor/bhz227

HALLONET M.E., TEILLET M.A., LE DOUARIN N.M. (1990). A new approach to the development of the cerebellum provided by the quail-chick marker system. Development 108: 19-31. https://doi.org/10.1242/dev.108.1.19

HAMZA M. M., REY S. A., HILBER P., ARABO A., COLLIN T., VAUDRY D., BUREL D. (2016). Early Disruption of Extracellular Pleiotrophin Distribution Alters Cerebellar Neuronal Circuit Development and Function. Molecular Neurobiology 53: 52035216. https://doi.org/10.1007/s12035-015-9450-5

HANAWAY J. (1967). Formation and differentiation of the external granular layer of the chick cerebellum. The Journal of Comparative Neurology 131: 1-13. https:// doi.org/10.1002/cne.901310102 
HANZEL M., ROOK V., WINGATE R. J. T. (2019). Mitotic granule cell precursors undergo highly dynamic morphological transitions throughout the external germinal layer of the chick cerebellum. Scientific Reports 9: 15218. https://doi. org/10.1038/s41598-019-51532-y

HAYDAR T. F., WANG F., SCHWARTZ M. L., RAKIC P. (2000). Differential Modulation of Proliferation in the Neocortical Ventricular and Subventricular Zones. The Journal of Neuroscience 20: 5764-5774. https://doi.org/10.1523/JNEUROSCI.20-15-05764.2000

KOMMATA V., DERMON C. R. (2018). Transient vimentin expression during the embryonic development of the chicken cerebellum. International Journal of Developmental Neuroscience 65:11-20. https://doi.org/10.1016/j.ijdevneu.2017.10.003

KURUMA A., INOUE T., MIKOSHIBA K. (2003). Dynamics of $\mathrm{Ca} 2+$ and $\mathrm{Na}+$ in the dendrites of mouse cerebellar Purkinje cells evoked by parallel fibre stimulation. European Journal of Neuroscience 18:2677-2689. https://doi.org/10.1111/j.14609568.2003.02977.x

LARSELL O., JANSEN J.(1967). he comparative anatomy and histology of the cerebellum, from myxinoids through birds: By Olof Larsell, edited by Jan Jansen. Univ. of Minnesota Press, Minneapolis.

LIU W., ZHANG Y., YUAN W., WANG J., LI S. (2012). A Direct Hippocampo-Cerebellar Projection in Chicken. The Anatomical Record: Advances in Integrative Anatomy and Evolutionary Biology 295: 1311-1320. https://doi.org/10.1002/ar.22515

MATARREDONA E. R., MURILLO-CARRETERO M., MORENO-LÓPEZ B., ESTRADA C. (2004). Nitric oxide synthesis inhibition increases proliferation of neural precursors isolated from the postnatal mouse subventricular zone. Brain Research 995: 274-284. https://doi.org/10.1016/j.brainres.2003.10.010

MECHA M., PENA-MELIAN A. L., BLANCO M. J. (2010). Microarchitectural changes during development of the cerebellar cortex. The International Journal of Developmental Biology 54: 691-698. https://doi.org/10.1387/ijdb.082670mm

MITSACOS A., DERMON C.R., STASSI K., KOUVELAS E.D. (1990). Localization ofl-glutamate binding sites in chick brain by quantitative autoradiography. Brain Research 513: 348-352. https://doi.org/10.1016/0006-8993(90)90480-Y

MONYER H., SEEBURG P.H., WISDEN W. (1991). Glutamate-operated channels: Developmentally early and mature forms arise by alternative splicing. Neuron 6: 799-810. https://doi.org/10.1016/0896-6273(91)90176-Z

PENA-MELIAN A. P., FONOLLA J. P., LOYZAGA P. G. (1986). The ontogeny of the cerebellar fissures in the chick embryo. Anatomy and Embryology 175: 119-128. https://doi.org/10.1007/BF00315462

PIRES R. S., REAL C. C., FOLADOR T. S., TELLINI N. R., TORRÃO A. S., BRITTO L. R.G. (2010). Differential response of AMPA and NMDA glutamate receptors of Purkinje cells to aging of the chicken cerebellum. Neuroscience Letters 478: 146149. https://doi.org/10.1016/j.neulet.2010.05.005

PLACHTA N. (2003). Nitric oxide is involved in establishing the balance between cell cycle progression and cell death in the developing neural tube. Experimental Cell Research 288: 354-362. https://doi.org/10.1016/S0014-4827(03)00215-5
POULSEN F. R., BLAABJERG M., MONTERO M., ZIMMER J. (2005). Glutamate receptor antagonists and growth factors modulate dentate granule cell neurogenesis in organotypic, rat hippocampal slice cultures. Brain Research 1051: 35-49. https:// doi.org/10.1016/j.brainres.2005.05.050

RAKIC P. (1971). Neuron-glia relationship during granule cell migration in developing cerebellar cortex. A Golgi and electonmicroscopic study in Macacus rhesus. The Journal of Comparative Neurology 141: 283-312. https://doi.org/10.1002/ cne.901410303

RAUVALA H. (1989). An 18-kd heparin-binding protein of developing brain that is distinct from fibroblast growth factors. The EMBO Journal 8: 2933-2941. https:// doi.org/10.1002/j.1460-2075.1989.tb08443.x

SOUTHAM E., EAST S. J., GARTHWAITE J. (1991). Excitatory Amino Acid Receptors Coupled to the Nitric Oxide/Cyclic GMP Pathway in Rat Cerebellum During Development. Journal of Neurochemistry 56: 2072-2081. https://doi. org/10.1111/j.1471-4159.1991.tb03468.x

STAMATAKIS A., BARBAS H., DERMON C. R. (2004). Late granule cell genesis in quail cerebellum. The Journal of Comparative Neurology 474: 173-189. https:// doi.org/10.1002/cne.20066

SUDAROV A., JOYNER A. L. (2007). Cerebellum morphogenesis: the foliation pattern is orchestrated by multi-cellular anchoring centers. Neural Development 2: 26. https://doi.org/10.1186/1749-8104-2-26

TANAKA M., MAEDA N., NODA M., MARUNOUCHI T. (2003). A Chondroitin Sulfate Proteoglycan PTPZ/RPTP $\beta$ Regulates the Morphogenesis of Purkinje Cell Dendrites in the Developing Cerebellum. The Journal of Neuroscience 23: 2804-2814 https://doi.org/10.1523/JNEUROSCI.23-07-02804.2003

TANG C., WANG M., WANG P., WANG L., WU Q., GUO W. (2019). Neural Stem Cells Behave as a Functional Niche for the Maturation of Newborn Neurons through the Secretion of PTN. Neuron 101: 32-44.e6. https://doi.org/10.1016/j. neuron.2018.10.051

TELLIOS V., MAKSOUD M. J. E., XIANG Y.Y., LU W.Y. (2020). Nitric Oxide Critically Regulates Purkinje Neuron Dendritic Development Through a Metabotropic Glutamate Receptor Type 1-Mediated Mechanism. The Cerebellum 19: 510-526. https://doi.org/10.1007/s12311-020-01125-7

VOUKELATOU G., ANGELATOY F., KOUVELAS E.D. (1986). The binding properties and regional ontogeny for [ $3 \mathrm{H}$ ] glutamic acid $\mathrm{Na}+$-independent and [ $3 \mathrm{H}$ ]kainic acid binding sites in chick brain . International Journal of Developmental Neuroscience 4: 339-349. https://doi.org/10.1016/0736-5748(86)90051-1

ZAGRIS N. (2001). Extracellular matrix in development of the early embryo. Micron 32: 427-438. https://doi.org/10.1016/S0968-4328(00)00011-1

ZAVITSANOU K., MITSACOS A., KOUVELAS E.D. (1994). Autoradiographic characterization of fhio-cyano-p-nitroquinoxaline-2,3-dione binding sites in adult chick brain. Neuroscience 62: 955-962. https://doi.org/10.1016/03064522(94)90486-3 